\title{
A
}

\section{Effect of Particle Size and Dispersion on Dielectric Properties in ZnO/Epoxy Resin Composites}

\author{
Wenhu Yang ${ }^{\dagger}$, Ran Yi, Xu Yang, Man Xu, Sisi Hui, and Xiaolong Cao \\ State Key Laboratory of Power Equipment and Electrical Insulation, Xi'an Jiaotong University, Xi'an, China
}

Received November 4, 2011; Revised March 26, 2012; Accepted March 28, 2012

\begin{abstract}
In this paper, ZnO-Epoxy nanocomposites (NEP) were prepared and epoxy composites that contain 5 wt\% micro $\mathrm{ZnO}$ (MEP) and deliberately not well dispersed nano ZnO (NDNEP) were also prepared for purpose of comparison. The effects of the particle size and dispersion of $\mathrm{ZnO}$ on dielectric properties of epoxy resin were chiefly studied. Test results showed that: at a loading of $5 \mathrm{wt} \%$, the three epoxy composites seem to have no significant difference on resistivity compared to epoxy resin; Dielectric constants of all the epoxy composites are also basically the same but they are bigger compared to that of the pure epoxy resin (unfilled); Dielectric dissipation factors ( $\tan \delta$ ) of NDNEP is greater than that of NEP and MEP. NEP has the minimum dielectric loss factor, whereas dielectric loss factors of the three epoxy composites are larger than that of the pure epoxy resin. The decreasing order of electrical breakdown strength for the three epoxy composites and for the pure epoxy resin is as follows: NEP $>$ MEP $>$ NDNEP $>$ EP. Finally, in order to explain the experimental results the aggregation interface phase was proposed. Furthermore, addition of well dispersed nano filler has proved to have a positive effect on the improvement of the dielectric properties of epoxy resin.
\end{abstract}

Keywords: Nano, Micro, Epoxy resin, Composites, Dielectric properties, Dispersion

\section{INTRODUCTION}

In 1970s, Japanese scholars proposed the concept of ultrafine particles and since then, immense development has been achieved. If ultrafine particles dispersed in a polymer with nanosize then, the so-called "nanocomposite" was formed. Addition of nano fillers to polymer can combine the stiffness, dimensional stability, toughness of inorganic materials with flexible, processible, dielectric properties of the polymer, and prepare highperformance polymer composites [1]. In the field of electrical engineering, researchers are more concerned about the dielectric properties of composites. Most of the studies have shown that nano fillers which were added to a polymer can improve its dielectric properties, such as resistivity, electrical breakdown strength, resistance to partial discharge, etc. [2], and they con-

${ }^{\dagger}$ Author to whom all correspondence should be addressed: E-mail: tiger-y@163.com

Copyright $\odot 2012$ KIEEME. All rights reserved.

This is an open-access article distributed under the terms of the Creative Commons Attribution Non-Commercial
License (http://creativecommons.org/licenses/by-nc/3.0) which permits unrestricted noncommercial use, License (http://creativecommons.org/licenses/by-nc/3.0) which permits unrestricted
distribution, and reproduction in any medium, provided the original work is properly cited. sidered that nanocomposites have promising application in the electrical power industry [3]. The phenomenon that nano materials possess unusual properties compared to the traditional materials was usually attributed to the "nano effect". Researchers have tried to find out the true reason behind "nano effect". TJ Lewis [4] and Nelson [5] proposed that the interface between nanofillers and a polymer plays an important role in the determination of the material properties. T. Tanaka [6,7] established a multi-shell model in order to explain the changes in the polymer dielectric properties upon the addition of nanofillers. However there are questions like, how the dielectric property of the polymer composites is affected by nano fillers, and how it changes if the nano fillers were aggregated inevitably. All these problems are not completely clarified and so, further research is required.

Epoxy resin (EP) is an insulation material. It is widely used in many electric apparatus, such as bushing, GIS, generator and solid cast transformer [8]. In order to reduce the expansion coefficient to prevent epoxy product separation from other parts at heat cycle, it was required to add fillers to the epoxy resin. With the addition of nano fillers, epoxy resin was also found to possess better electrical properties. Zhe Li [9] insisted that the addition of 
nano fillers will provide a better approach for increasing the dielectric breakdown strength and the partial discharge resistance of micro-filled epoxy composites. Jae-Jun Park [10] verified that AC insulation breakdown strength of epoxy resin was remarkably improved by the addition of intercalated silicates. T, P. Preetha [11] found out that AC breakdown strength for epoxy composite containing $5 \mathrm{wt} \%$ nano alumina fillers is higher compared to that of the unfilled epoxy. Still, the problems that are mentioned above have not been resolved and so, the epoxy resin was applied as a polymer matrix to try to find the answer.

In this paper, Zinc oxide (ZnO), an important wide band-gap semiconducting material with the potential for different applications was selected as fillers for the preparation of $\mathrm{ZnO}$-epoxy composites. Moreover for the purpose of comparison, epoxy composites containing micron $\mathrm{ZnO}$ and not well-dispersed nano $\mathrm{ZnO}$ were also prepared. Then, the dielectric properties of the three epoxy composites and the mechanism of nano effect were studied.

\section{EXPERIMENTS}

\subsection{Materials}

The epoxy resin and curing agent which were selected in this experiment were bisphenol A epoxy resin and acid anhydride type curing agent methyl hexahydrophthalic anhydride. They were most commonly used in electrical engineering. The accelerating agent, dimethyl benzyl amine was used to reduce the curing temperature of epoxy resin and also to shorten the curing time. The nano $\mathrm{ZnO}$ filler (average particle size $=20 \mathrm{~nm}$ ) was previously treated by the manufacturer with aminopropyltriethoxysilane (a kind of silane coupling agent named as KH550 in China) to improve its dispersibility. The micro $\mathrm{ZnO}$ filler whose particle size is $2-5 \mu \mathrm{m}$ was also treated by using KH550 silane agent before addition in epoxy resin. The micro $\mathrm{ZnO}$ powder and $2 \mathrm{wt} \% \mathrm{KH} 550$ were put in alcohol in a beaker, stirred for about 0.5 $\mathrm{h}$, and then, the powder was filtered out of the mixed solution. After drying at $80^{\circ} \mathrm{C}$, the power was grinded and it was put into a desiccator for use.

\subsection{Sample preparation}

Firstly, epoxy resin was placed in a beaker and proper proportions of acetone were added for dilution, then, the required amounts of nanoparticles were also added. In order to preliminarily disperse nanoparticles, the mixture was stirred for $30 \mathrm{~min}$ by using a high-shear mechanical mixer at a speed of 10,000 rpm. Subsequently, the nanofillers were further dispersed for $30 \mathrm{~min}$ by using ultrasonic machine. After ensuring the total evaporation of acetone from the beaker, fixed percentages of curing and accelerating agents were added to the mixture (epoxy resin: curing agent: accelerating agent weight ratio $=100: 90: 2$ ). Then, the mixture was well stirred and was degassed in a vacuum for about $0.5 \mathrm{~h}$ at $50^{\circ} \mathrm{C}$. Finally, the fluid was cast in to a plate mold and it was oven-cured at $120^{\circ} \mathrm{C}$ for $8 \mathrm{~h}$. After natural cooling to room temperature, the samples were collected for measurement. The epoxy composite samples that were prepared for the dielectric characterization were of $100 \mathrm{~mm}$ diameter and $1 \mathrm{~mm}$ thickness.

Epoxy composite containing $5 \mathrm{wt} \%$ micro $\mathrm{ZnO}$ and deliberately not well dispersed nano $\mathrm{ZnO}$ were also prepared for comparison. The preparation of micron $\mathrm{ZnO}$-epoxy composite was consistent with that of nanocomposites except for the process of ultrasonic treatment which was omitted. In the preparation processing of epoxy composite containing deliberately not well dispersed nano $\mathrm{ZnO}$, shear dispersion and ultrasonic treatment process were omitted and only one hour electric mixer mixing was used.

To facilitate description, epoxy composites containing nano $\mathrm{ZnO}$, micro $\mathrm{ZnO}$ and deliberately not well dispersed nano $\mathrm{ZnO}$ in short are respectively named as NEP, MEP and NDNEP in this paper hereinafter.

\subsection{Measurement}

Resistivity was measured by using high resistance meter (type ZC36) at a voltage of DC $1 \mathrm{kV}$. Dielectric constant and dissipation factor test were carried out by using the high-voltage Schering Bridge (type 2801, Tettex, Swiss) at a voltage of about AC $2 \mathrm{kV}$ and a frequency of $50 \mathrm{~Hz}$. Electric breakdown strength was tested in oil with sphere-sphere electrode at AC voltage and a voltage rise rate of $2 \mathrm{kV} / \mathrm{s}$. All the test measurements were taken at ambient temperature and pressure.

\section{DISPERSION}

Scanning electron microscopy (SEM) was used to observe dissipation for the three kinds of epoxy composites. SEM photographs of epoxy composites containing $5 \mathrm{wt} \%$ are shown in Fig. 1. Only a small amount of nano fillers were aggregated as shown in Fig. 1(a) and most of the nano fillers existed as single particles. Micro $\mathrm{ZnO}$ was also well dispersed in epoxy resin and it can be seen in Fig. 1(b). According to Fig. 1(c), the maximum aggregation dimension is up to $5 \mu \mathrm{m}$ and it can be concluded that the nano $\mathrm{ZnO}$ particles will aggregate in epoxy resin without using high shear dispersion and ultrasound treatment.

\section{RESULTS AND DISCUSSION}

\subsection{Resistivity}

The resistivity of the three kinds of composites and pure EP are shown in Fig. 2. The resistivity of MEP and NDNEP containing $5 \mathrm{wt} \%$ fillers are smaller compared to that of pure EP, but the difference is not very obvious. $\mathrm{ZnO}$ is a semiconducting material, but the resistivity of epoxy composites doesn't decrease much (even increase for addition of nano $\mathrm{ZnO}$ fillers), So, we consider that the resistivity of epoxy composites has no relation with the resistivity of $\mathrm{ZnO}$ particles but only with their particle size and dispersion.

The results may be due to the interface between the fillers and epoxy matrix. If the nano filler loading is low then, the interface has trend to either limit or reduce the charge carrier in the composite mixture, and this results in decreased conductivity. When the loading is high, the impurities that were introduced by the nanoparticles could not be omitted, then the number of impurity ions would increase and exceed the number of carriers that interface can absorbed, so the resistivity of $5 \mathrm{wt} \%$ NEP is lower than that of $1 \mathrm{wt} \%$ NEP. In MEP, there is no interface effect introduced by the nano particles and as a result, its resistivity is less than that of NEP. NDNEP may contain very small amount of well dispersed nano-particles and so, the resistivity of NDNEP is slightly higher compared to that of MEP.

\subsection{Dielectric constant and dielectric dissipation factor}

Figure 3 indicates the dielectric constant of three kinds of composites and pure EP. It shows that the dielectric constant of MEP and NDNEP are almost similar with that of NEP at filler 
(a)

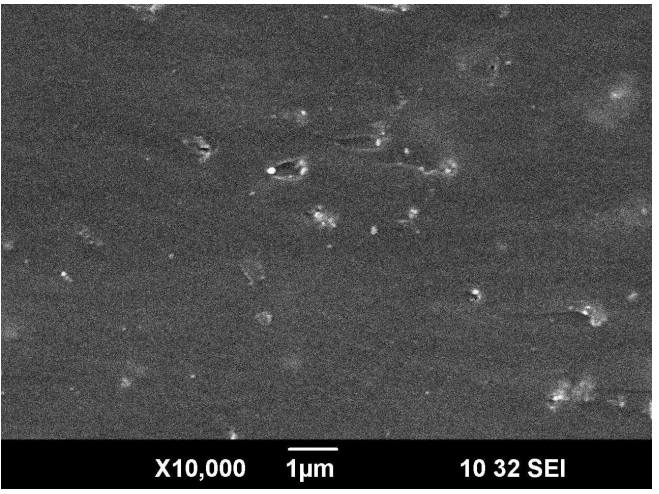

(b)

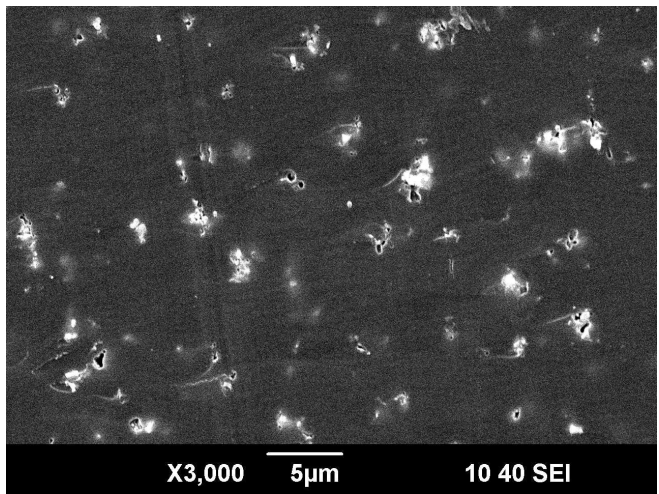

(c)

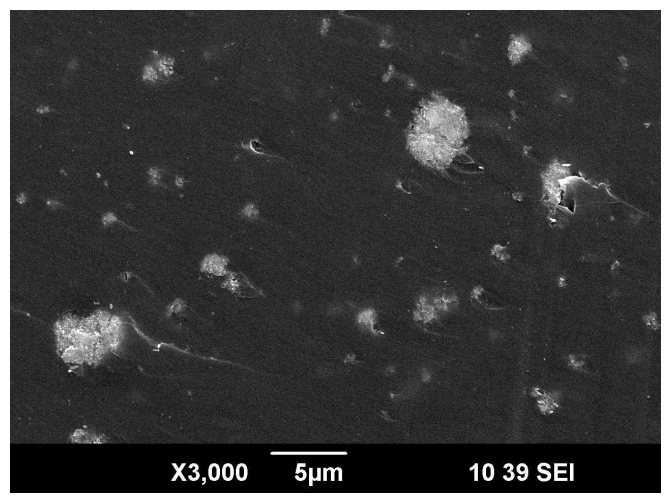

Fig. 1. SEM photographs of epoxy composites containing $5 \mathrm{wt} \%$ fillers (a) NEP, (b) MEP, and (c) NDNEP.

loading of $5 \mathrm{wt} \%$. Therefore, the dielectric constant can be considered to have relation only with filler loadings. The dielectric constant of epoxy will have the same value if same filler loading was added and this is regardless of its dispersion and size.

Figure 4 shows that the dielectric dissipation of MEP has a weak increase compared to that of NEP, and it was calculated to be around $6.5 \times 10^{-4}$. The dielectric dissipation of NDNEP is greatly larger compared to that of NEP, and the difference value is about $3.21 \times 10^{-3}$

Some literatures have reported that $\mathrm{TiO}_{2}$ nano fillers have resulted in an anomalous reduction in the permittivity of epoxy resin $[12,13]$ while others have concluded that $\varepsilon_{r}$ of layered silicate nanocomposites is less than that of pure EP [14]. Moreover, a paper has also stated that the permittivity of the nanocomposites under $1 \mathrm{wt} \%$ nano $\mathrm{ZnO}$ is less compared to that of unfilled EP [15]. So, if nano fillers were added at proper percentage, the dielectric constant of a polymer composite would decrease, which is caused by "nano effect". When filler loading is high, the impact of "nano effect" on the dielectric constant is not so obvious and high dielectric constant of filler and interfacial polarization will

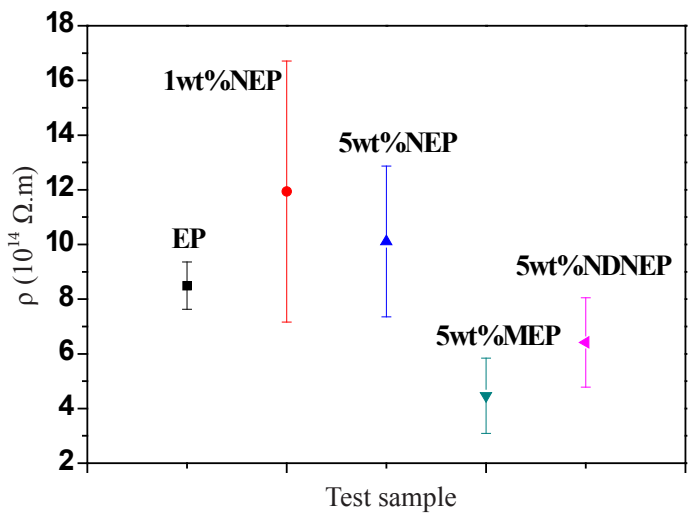

Fig. 2. Resistivity of EP and ZnO/EP composites.

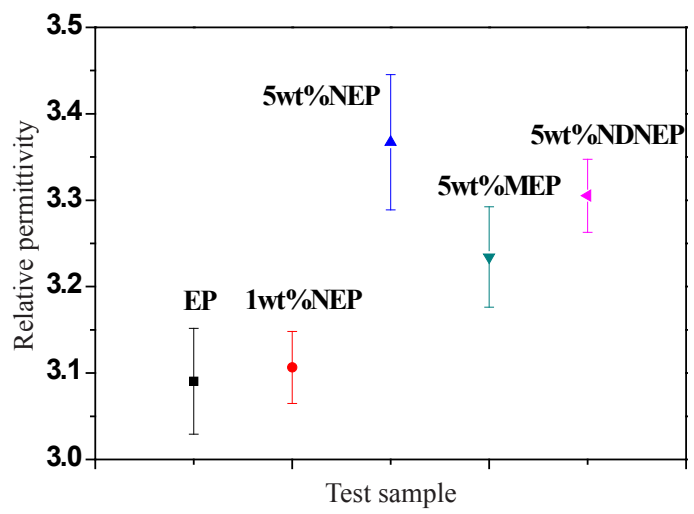

Fig. 3. Dielectric constant of EP and ZnO/EP composites.

Table 1. Phase composition of three kinds of epoxy composites.

\begin{tabular}{lcccc}
\hline Material & Matrix Phase & Filler Phase & $\begin{array}{c}\text { Interface } \\
\text { Phase }\end{array}$ & $\begin{array}{c}\text { Aggregation } \\
\text { Interface } \\
\text { Phase }\end{array}$ \\
\hline \hline NEP & Main & $5 \mathrm{wt} \%$ & Much & Little \\
MEP & Main & $5 \mathrm{wt} \%$ & Little & Little \\
NDNEP & Main & $5 \mathrm{wt} \%$ & Little & Much \\
EP & Whole & 0 & 0 & 0 \\
\hline
\end{tabular}

dominate the change of the dielectric constant of composites. So, on loading of $5 \mathrm{wt} \%$, the dielectric constant of the three kinds of composites is higher than that of pure EP. Slight difference in the dielectric constant of the three kinds of composites may also be due to the interfacial polarization, and NEP contains most of the nano-particles. Moreover, NDNEP may contain very small amount of well dispersed nano-particles. Therefore, the dielectric constant of MEP is slightly lower compared to that of NDNEP and of NEP. For the dielectric dissipation factor, the impact of "nano effect" still exists at the loading of $5 \mathrm{wt} \%$. The reduced dielectric loss tangent of NEP compared to that of MEP marked in Fig. 4 may be due to this "nano effect". However, as the dielectric loss introduced by fillers increases faster, the dielectric dissipation factor of $5 \mathrm{wt} \%$ NEP is greater than that of pure EP. NDNEP has the highest dielectric dissipation and this should be attributed to its filler aggregation.

\subsection{Electric breakdown strength}

As seen from Fig. 5, the breakdown strength of 5 wt\% NEP 


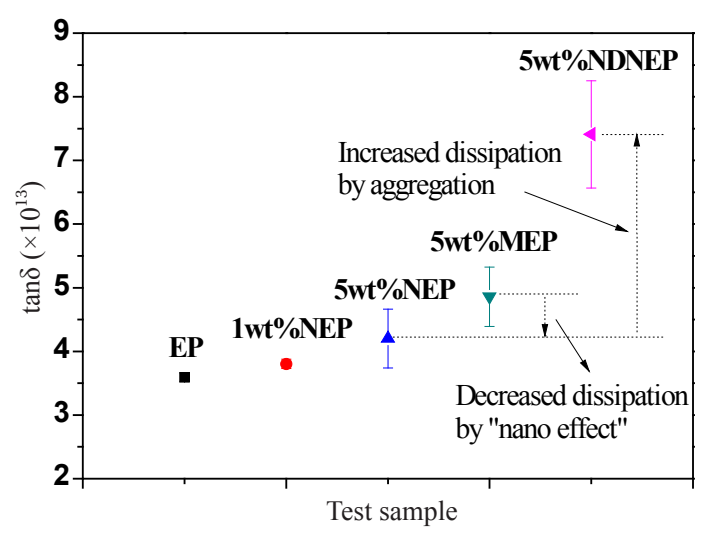

Fig. 4. $\tan \delta$ of $\mathrm{EP}$ and $\mathrm{ZnO} / \mathrm{EP}$ composites.

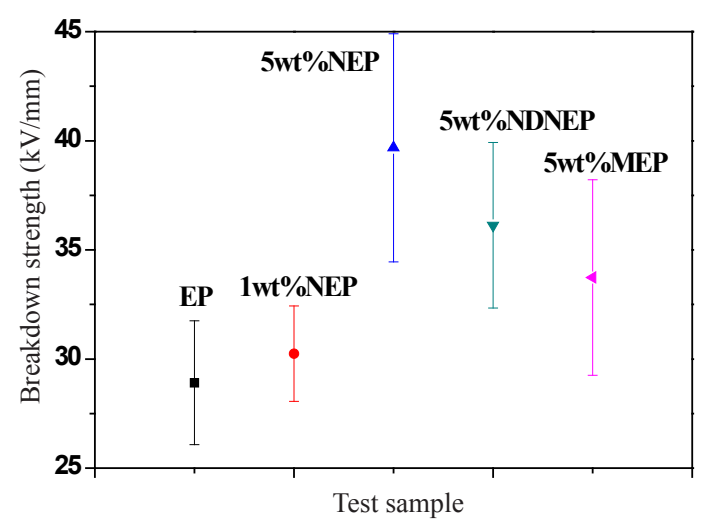

Fig. 5. Breakdown strength of EP and $\mathrm{ZnO} / \mathrm{EP}$ composites.

increases by $37 \%$ compared to that of pure EP. The breakdown strength of NEP is also higher than that of MEP and NDNEP. On the other hand, the breakdown strength of MEP and NDNEP is higher than that of pure epoxy. This is beyond expectations. One possible reason for this is that a small amount of nano particles may exist in MEP and NDNEP. However, we can still deduce that the filler dispersion has great impact on the breakdown strength of epoxy composites, as the breakdown strength of NEP is higher compared to that of NDNEP by about $20 \%$.

We considered that the improvement of electric breakdown of NEP also has relation with interface, perhaps some electrons which may cause breakdown were trapped at the interface. Numerous researches have been carried out on the breakdown strength of composites $[15,16]$. However, until now there is no unified theory to explain the nano effect on the breakdown strength of polymer composites.

\section{MODEL OF POLYMER COMPOSITES CONSTITUENTS}

From the above description, it can be deduced that the interface between fillers and epoxy matrix plays a significant role in determining the properties of nanocomposites. We argued that the interface in the filler aggregation should be considered in polymer composites. This is due to the nano particles which cannot be completely well dispersed in most of the polymer composites. Some of the nano particles will aggregate inevitably. The interface between them is completely different with the interface between the polymer and nano fillers, and it may mainly

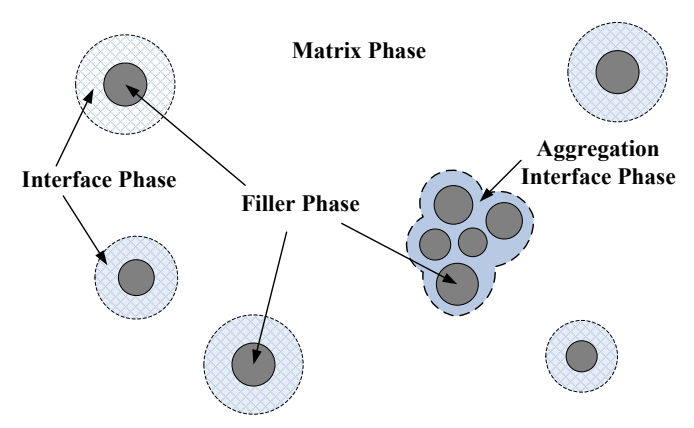

Fig. 6. Diagrammatic representation of the construction of polymer composites.

constitute of surface treatment agents and impurities that were introduced by physical adsorption. With a relatively weak chemical bond in this area, it trends to own high dielectric loss.

Therefore as shown in Fig. 6, polymer composites should constitute of four basic phases.

Matrix phase is the largest component of the composite phase and this phase, determines the basic physical and chemical properties of composites. Filler phase is the particles in composites and it is generally very small compared to the Matrix phase. The property of the interface phase should be impacted by chemical bonds between fillers and the polymer. The proportion of the interface phase is relative to its thickness which is unknown until now, but it must be more in the nanocomposites than in microcomposites and composites with not well dispersed nano fillers. Aggregation interface phase is little in the nanocomposites and microcomposites, but it is more in composites with no well-dispersed nano fillers. The phase composition of the three kinds of epoxy composites is shown in Tab.1.

By comparing the contents of Tab.1 with the electrical properties of composites that are mentioned above, the following can be deduced. If the composites contained same amount of the filler phase then, the dielectric constant of composites should have the same value and so, the three kinds of composite materials have nearly the same dielectric constant. Moreover, if the interface phase was more, the breakdown strength of composites can be improved and so, NEP tends to have higher breakdown strength compared to MEP, NDNEP and pure epoxy. Furthermore, if aggregation interface phase was much, the dielectric loss must be high and so, NDNEP has high dielectric dissipation factor.

\section{CONCLUSIONS}

In this paper, ZnO-Epoxy nanocomposites with good dielectric properties have been prepared and following conclusions can be drawn.

1. At a loading of $5 \mathrm{wt} \%$, the three epoxy composites seem to have no significant difference on the resistivity with pure epoxy resin.

2. The dielectric constant of epoxy composites is closely related with $\mathrm{ZnO}$ filler loadings. Generally, the epoxy composites with a greater amount of $\mathrm{ZnO}$ fillers tend to have greater dielectric constant. The dielectric loss of epoxy composites has a relation with both the filler content and also filler dispersion, the greater the filler amount was and the worse the filler scattered, the greater the loss would be. Particularly, the dispersion has great impact on the dielectric loss.

3. The breakdown strength of $5 \mathrm{wt} \%$ NEP is higher than that 
of pure epoxy resin by nearly $40 \%$. This is more conductive to the application of epoxy in electrical engineering. Poor dispersion and addition of micro fillers instead of nano fillers will make the breakdown strength of epoxy composites reduced.

In our opinion, the composition of polymer composites can be divided into four phases: matrix phase, filler phase, interface phase and aggregation interface phase. With this theory, the changes in the electrical properties of epoxy composites can be qualitatively explained, and it can be deduced that well dispersion of nano fillers benefit to improve the dielectric properties of epoxy composites.

\section{REFERENCES}

[1] Liu Jiping and Hao Xiangyang, Polymer nanocomposite materials (Science press, Beijing, 2009) p.11.

[2] T. Tanaka, G. C. Montanari and R. Mulhaupt, IEEE Trans. Dielectr. Electr. Insul. 11, 763(2004) [DOI: 10.1109/ TDEI.2004.1349782].

[3] Y. Cao, P. C. Irwin and K. Younsi, IEEE Trans. Dielectr. Electr. Insul. 11, 797 (2004).

[4] T. J. Lewis, IEEE Trans. Dielectr. Electr. Insul. 11, 739(2004) [DOI: 10.1109/TDEI.2004.1349779].

[5] M. Roy, J. K. Nelson, C. W. Reed, R. K. MacCrone, R. J. Keefe, W. Zenger, and L. S. Schadler, IEEE Trans. Dielectr. Electr. Insul. 12, 1273(2005) [DOI: 10.1109/TDEI.2005.1511089].
[6] T. Tanaka, M. Kozako, N. Fuse, and Y. Ohki, IEEE Trans. Dielectr. Electr. Insul. 12, 669(2005) [DOI: 10.1109/TDEI.2005.1511092].

[7] T. Tanaka, IEEE Trans. Dielectr. Electr. Insul. 12, 914 (2005) [DOI: 10.1109/TDEI.2005.1522186].

[8] D. A. Bolon, IEEE Electr. Insul. Mag. 11, 10(1995) [DOI: $10.1109 / 57.400759]$.

[9] Z. Li, K. Okamoto, Y. Ohki, and T. Tanaka, IEEE Trans. Dielectr. Electr. Insul. 18, 675(2011) [DOI: 10.1109/TDEI.2011.5931052].

[10] J. J. Park and S. S. Kwon, Trans. Electr. Electron. Mater. 12 135(2011) [DOI: 10.4313/TEEM.2011.12.4.135].

[11] P. Preetha and M. J. Thomas, IEEE Trans. Dielectr. Electr. Insul. 18, 1526 (2011)

[12] J. K. Nelson, J. C. Fothergill, L. A. Dissado, and W. Peasgood, 2002 Annual Report Conference on Electrical Insulation and Dielectric Phenomena (Mexico)(Cancun, Mexico, 2002 Oct. 2024)p.295.

[13] J. K. Nelson and Y. Hu, Proceeding of the 2004 IEEE International Conference on Solid Dielectrics (France) (Toulouse, France, 2004 Jul. 05-09) p. 832.

[14] T. Imai, Y. Hirano, H. Hirai, S. Kojima, and T.Shimizu, Conference Record of the 2002 IEEE International Symposium on Electrical Insulation(USA)(Boston, MA, USA, 2002Apr.07-10) p.379 [ DOI:10.1109/ELINSL.2002.995955].

[15] S. Singha and M. J. Thomas, IEEE Trans. Dielectr. Electr.l Insul. 16, 531 (2009).

[16] T. Imai, F. Sawa, T. Nakano, T. Ozaki, T. Shimizu, M. Kozako, and T. Tanaka, IEEE Trans. Dielectr. Electr. Insul. 13, 319 (2006) [DOI: 10.1109/TDEI.2006.1624276]. 